\title{
Specific insulin and proinsulin in normal glucose tolerant first-degree relatives of NIDDM patients
}

\section{R. Coifman, \\ I.S. Dalbosco, \\ E.M.K. Russo and \\ R.S. Moisés}

Disciplina de Endocrinologia, Universidade Federal de São Paulo, Escola Paulista de Medicina, São Paulo, SP, Brasil

\section{Correspondence}

R.S. M oisés

Disciplina de Endocrinologia

EPM, UNIFESP

Rua Botucatu, 740

Caixa Postal 20266

04034-970 São Paulo, SP

Brasil

Fax: + 55-11-570-6636

E-mail: rmoises@endocrino.epm.br

Publication supported by FAPESP.

Received M arch 3, 1998

Accepted O ctober 20, 1998

\section{Abstract}

In order to identify early abnormalities in non-insulin-dependent diabetes mellitus (NIDDM) we determined insulin (using an assay that does not cross-react with proinsulin) and proinsulin concentrations. The proinsulin/insulin ratio was used as an indicator of abnormal $\beta$ cell function. The ratio of the first 30-min increase in insulin to glucose concentrations following the oral glucose tolerance test (OGTT; $\mathrm{I}_{30-0} / \mathrm{G}_{30-0}$ ) was taken as an indicator of insulin secretion. Insulin resistance $(\mathrm{R})$ was evaluated by the homeostasis model assessment (HOMA) method. True insulin and proinsulin were measured during a 75-g OGTT in 35 individuals: 20 with normal glucose tolerance (NGT) and without diabetes among their first-degree relatives (FDR) served as controls, and 15 with NGT who were FDR of patients with NIDDM. The FDR group presented higher insulin (414 pmol/1 vs 195 $\mathrm{pmol} / \mathrm{l} ; \mathrm{P}=0.04)$ and proinsulin levels (19.6 pmol/1 vs $12.3 \mathrm{pmol} / \mathrm{l} ; \mathrm{P}$ $=0.03$ ) post-glucose load than the control group. When these groups were stratified according to BMI, the obese FDR $(\mathrm{N}=8)$ showed higher fasting and post-glucose insulin levels than the obese NGT (N =9) (fasting: $64.8 \mathrm{pmol} / \mathrm{l}$ vs $7.8 \mathrm{pmol} / \mathrm{l} ; \mathrm{P}=0.04$, and $60 \mathrm{~min}$ postglucose: $480.6 \mathrm{pmol} / 1$ vs $192 \mathrm{pmol} / \mathrm{l} ; \mathrm{P}=0.01$ ). Also, values for HOMA (R) were higher in the obese FDR compared to obese NGT (2.53 vs 0.30; $\mathrm{P}=0.075)$. These results show that FDR of NIDDM patients have true hyperinsulinemia (which is not a consequence of cross-reactivity with proinsulin) and hyperproinsulinemia and no dysfunction of a qualitative nature in B-cells.

\section{Introduction}

Non-insulin-dependent diabetes mellitus (NIDDM) is a heterogeneous disorder characterized by insulin resistance, decreased insulin secretion and increased hepatic glucose production. The role of these abnormalities as the earliest or primary causative
Key words

- Insulin

- NIDDM

- Proinsulin

- First-degree relatives factors of NIDDM is controversial. However, studies on individuals at high risk to develop the disease, such as offspring of patients with NIDDM and certain population groups, have provided important information. A decrease in insulin sensitivity has been found to precede and to predict the development of NIDDM, possibly occurring 
15 to 25 years before the clinical onset of the disease in genetically predisposed individuals (1-3).

In the present study we determined concentrations of proinsulin and insulin (using an assay that does not cross-react with proinsulin) in response to an oral glucose load in individuals with normal glucose tolerance (NGT) who were relatives of NIDDM patients and in control individuals with no family history of diabetes mellitus.

\section{Subjects and Methods}

Twenty-seven non-diabetic first-degree relatives (FDR) of NIDDM and 21 nondiabetic subjects with no family history of diabetes were studied. All subjects underwent a standard 75-g oral glucose tolerance test (OGTT) and were classified as having NGT, impaired glucose tolerance (IGT) or diabetes mellitus (DM) on the basis of the World Health Organization criteria (4). Only the subjects with NGT were included in the study, while 12 relatives (4 with NIDDM and 8 with IGT) and 1 control with NIDDM were excluded. Therefore, the study population comprised 35 individuals: 20 subjects with normal glucose tolerance and without diabetes among their FDR (NGT group, 8 men and 12 women) served as normal controls, and 15 with normal glucose tolerance and FDR of patients with NIDDM (FDR group, 5 men and 10 women). There were no differences in age, sex distribution and body

Table 1 - Clinical characteristics of study subjects.

Data are reported as medians. NGT, Normal glucose tolerance; FDR, first-degree relatives; $L$, nonobese; $O B$, obese.

\begin{tabular}{llrcc}
\hline Group & Sub-group & N (M/F) & Age (years) & BMI $\left(\mathrm{kg} / \mathrm{m}^{2}\right)$ \\
\hline NGT & & $20(8 / 12)$ & 31.5 & 25.2 \\
& NGT-L & $11(6 / 5)$ & 30.0 & 23.4 \\
& NGT-OB & $9(2 / 7)$ & 44.0 & 31.3 \\
FDR & & $15(7 / 8)$ & 47.0 & 27.0 \\
& FDR-L & $7(4 / 3)$ & 47.0 & 24.4 \\
& FDR-OB & $8(3 / 5)$ & 43.5 & 31.0
\end{tabular}

mass index (BMI) between groups. NGT and FDR groups were further divided into obese (OB) with a BMI $\geq 25 \mathrm{~kg} / \mathrm{m}^{2}$ for women and $\geq 27 \mathrm{~kg} / \mathrm{m}^{2}$ for men, and nonobese (L). The clinical characteristics of the study population are given in Table 1 .

After a 12-h fast, blood for the determination of glycemia, insulinemia and proinsulinemia was withdrawn from each subject at $0,30,60,90,120$ and $180 \mathrm{~min}$ after the ingestion of $75 \mathrm{~g}$ glucose.

Plasma glucose was measured by the glucose oxidase method (5). Proinsulin was determined by an immunofluorimetric assay using monoclonal antibodies as previously described (6). Plasma insulin was also measured by a previously reported immunofluorimetric method (7). In this assay, two monoclonal antibodies against insulin were produced: one was used for capture and the other, labelled with europium, was used as tracer antibody. The assay showed no crossreactivity with intact human proinsulin, des 31-32 proinsulin, split 32-33 (both produced during proinsulin processing) and C-peptide. The area under the glucose, insulin and proinsulin curves was calculated as the sum of half the fasting value plus the sum of the values obtained at 30,60,90 and $120 \mathrm{~min}$ and half the values obtained at $180 \mathrm{~min}(8)$.

The proinsulin/insulin molar ratio (PI/I) was determined under fasting conditions. Insulin secretion was measured as the ratio of the increase in insulin to the increase of glucose concentration at $30 \mathrm{~min}$ of the oral glucose tolerance test $\left(\mathrm{I}_{30-0} / \mathrm{G}_{30-0}\right)(9)$. Insulin resistance $(R)$ was evaluated using the homeostasis model assessment, HOMA (10).

\section{Statistical analysis}

The Mann-Whitney and Fisher exact tests were used to compare two independent groups not normally distributed. A P value $<0.05$ was considered statistically significant in all tests. 


\section{Results}

First-degree relatives of NIDDM patients had a higher prevalence of IGT or NIDDM diagnosed by the OGTT compared to the control group $(12 / 27$ vs $1 / 21 ; \mathrm{P}=0.02)$.

Mean fasting plasma glucose was not significantly different between the FDR group and their controls (NGT group). However, after the oral glucose load, plasma glucose levels showed a larger increase in the FDR than in the controls at 60 min (Figure 1).

Also, the insulin levels at $60 \mathrm{~min}$ were higher in the FDR group than in the NGT group (Figure 2A). When these groups were subdivided on the basis of BMI, no significant differences in insulin levels were detected between the nonobese subgroups (Figure 2B). In contrast, in the obese subgroups, the relatives (FDR-OB) showed higher fasting and 60-min post-glucose insulin levels $(\mathrm{P}<0.05)$ compared with control (NGT-OB) (Figure 2C). Figure 3A shows the plasma proinsulin response during the OGTT of the relatives and the controls. The FDR group had higher values at 90 min compared to the NGT group. No differences were found between NGT-L and FDR-L (Figure 3B) or between NGT-OB and FDR-OB (Figure 3C). However, when obese and nonobese subjects from the NGT group were compared, the NGT-OB had higher proinsulin at all times along the curve than the NGT-L $(\mathrm{P}<0.05)$. In contrast, no difference was found between obese and nonobese subjects in the FDR group.

No differences were found between the NGT and FDR groups with regard to the molar ratio between proinsulin and insulin in the fasting state. Similarly, the $\mathrm{I}_{30-0} / \mathrm{G}_{30-0}$ ratio, used as an indicator of insulin secretion, did not differ between the two groups. Insulin resistance assessed by the HOMA method did not differ between the two groups (Table 2). However, a trend to higher values was observed in the FDR-OB subgroup compared to NGT-OB (2.53 vs 0.30; $\mathrm{P}=0.075)$.

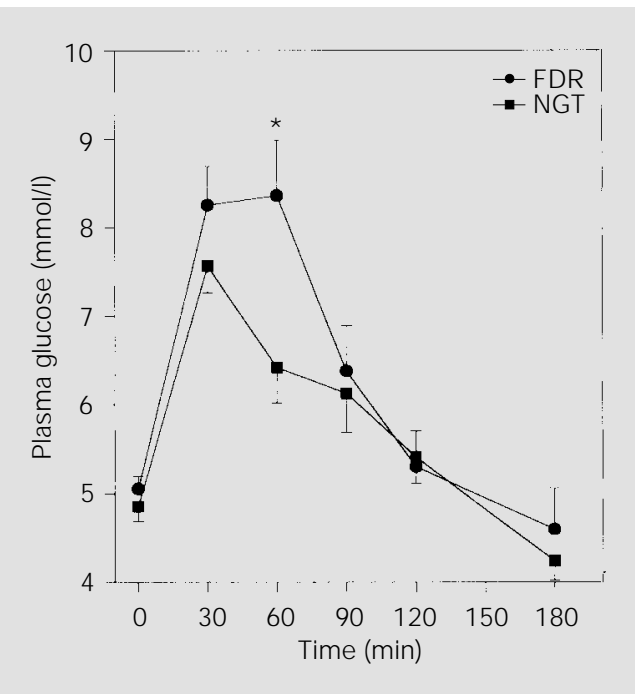

Figure 1 - Plasma glucose levels (mean \pm SEM) during the oral glucose tolerance test in control subjects (NGT, N = 20) and firstdegree relatives ( $F D R, N=15$ ). $* \mathrm{P}<0.05$ compared to control group (Mann-Whitney test).

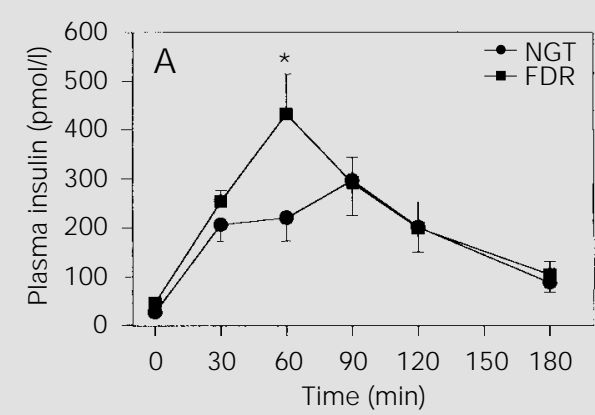

Figure 2 - Plasma insulin levels (mean \pm SEM) during the oral glucose tolerance test. A, Control subjects (NGT, N $=20$ ) and first-degree relatives with normal glucose tolerance (FDR, $\mathrm{N}=$ 15). B, Nonobese control group (NGT-L, N = 11) and nonobese relatives with normal glucose tolerance (FDR-L, $N=7$ ). C, Obese control subjects (NGT$\mathrm{OB}, \mathrm{N}=9$ ) and obese relatives with normal glucose tolerance (FDR-OB, $\mathrm{N}=8$ ). *P<0.05 compared to control group (MannWhitney test). 
Figure 3 - Plasma proinsulin levels (mean \pm SEM) during the oral glucose tolerance test. A, Control subjects (NGT, N = 20) and first degree-relatives with normal glucose tolerance (FDR, $\mathrm{N}=$ 15). B, Nonobese control subjects (NGT-L, N = 11) and nonobese relatives with normal glucose tolerance (FDR-L, $\mathrm{N}=$ 7). C, Obese control subjects (NGT-OB, N = 9) and obese relatives with normal glucose tolerance (FDR-OB, $\mathrm{N}=8$ ). $* \mathrm{P}<0.05$ compared to control group (Mann-Whitney test).

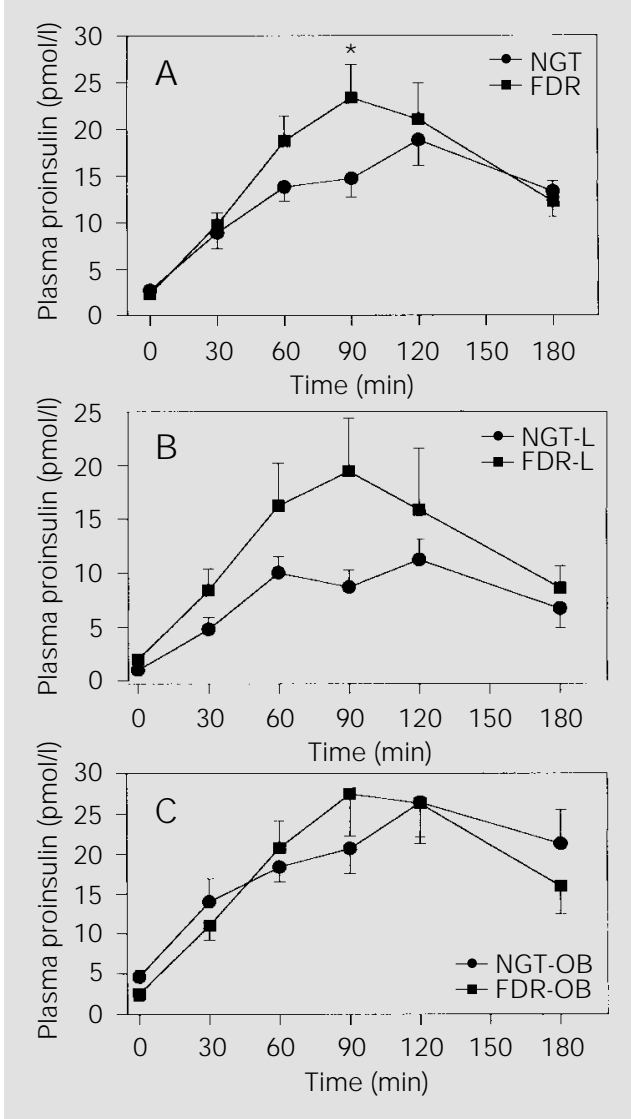

Table 2 - Metabolic measurements of control subjects (NGT) and relatives (FDR).

Data are reported as median (range). $\mathrm{PI} / \mathrm{I}$, Proinsulin/ insulin ratio; $I_{30-0} / \mathrm{G}_{30}-0$, ratio of the 30-min increment of insulin to glucose concentrations following the OGTT: HOMA, homeostasis model assessment.

\begin{tabular}{lccc}
\hline & $\begin{array}{c}\text { NGT } \\
(\mathrm{N}=20)\end{array}$ & $\begin{array}{c}\text { FDR } \\
(\mathrm{N}=15)\end{array}$ & P value \\
\hline $\mathrm{PI} / \mathrm{l}(\%)$ & $16.97(2.2-58.6)$ & $5.48(3.4-9.0)$ & 0.26 \\
$\mathrm{I}_{30-0 / \mathrm{G}_{30} 0}$ & $4.15(1.0-5.9)$ & $2.85(2.1-7.3)$ & 0.50 \\
HOMA (R) & $0.98(0.1-3.8)$ & $1.87(0.1-5.2)$ & 0.16
\end{tabular}

\section{Discussion}

In the present study, both plasma insulin and proinsulin levels after oral glucose loading were higher in subjects with normal glucose tolerance and first-degree relatives of patients with NIDDM compared to subjects without a family history of diabetes. When these subjects were subdivided according to BMI, among obese individuals those who were relatives of NIDDM patients presented significantly higher insulin levels under fasting conditions and after glucose loading and a trend to higher values in relative insulin resistance as determined by HOMA. These data indicate that, regardless of obesity, individuals with normal glucose tolerance and a family history of diabetes are more insulin resistant than those without diabetes among their first-degree relatives.

The results of previous studies on insulin and proinsulin levels in relatives of patients with NIDDM have been contradictory. Gelding et al. (11) and Roder et al. (12) reported increased fasting insulin, but not proinsulin, in first degree relatives of patients with NIDDM, while others (13) found that both insulin and proinsulin were increased among the relatives. Kahn et al. (14), in a prospective study on Japanese-American men, a population with a high prevalence of DM, observed that subjects who subsequently developed diabetes had higher proinsulin levels at baseline than those who continued to have NGT or IGT. These data indicate that an increase in proinsulin levels may be a risk factor for the subsequent development of non-insulin-dependent diabetes mellitus.

The importance of insulin resistance and of abnormal insulin secretion as a primary factor in the development of diabetes mellitus is still a controversial matter. Haffner et al. (15) observed that among Mexican-Americans with normal glucose tolerance, both insulin resistance and a decrease in insulin secretion were predictive factors for the development of NIDDM. In the present study, in which insulin secretion was assessed on the basis of the ratio of the increased insulin to increased glucose ratio at $30 \mathrm{~min}$ following OGTT, no significant differences were observed among individuals with normal glucose tolerance with or without a family history of diabetes, even when they were subdivided according to body mass index. 
An increased proportion of proinsulin to insulin, i.e., an increase in the proinsulin/ insulin ratio, is thought to reflect abnormal B-cell function (16). This alteration may be due to an intrinsic abnormality in the conversion of proinsulin to insulin or may be the result of an increased demand for insulin leading to the release of immature granules rich in proinsulin (17). Several studies have demonstrated a disproportionate increase in proinsulin in patients with NIDDM (18-20); however, few data are available about highrisk subjects with normal glucose tolerance. Haffner et al. (15) have shown that nondiabetic Mexican-Americans with a parental history of diabetes have a disproportionate elevation in proinsulin relative to insulin. In contrast, two other reports concerning Pima Indians (19) and Finnish subjects (20) did not find an increase in the proinsulin/insulin ratio. Similarly, among the individuals evaluated in the present study we did not find a qualitative change in B-cell function when subjects with normal glucose tolerance with and without a family history of diabetes were compared. One of the possible explanations for this discrepancy may be the ethnic difference of the groups studied. Furthermore, previous reports showed that the increase in the proinsulin/insulin ratio is associated with the severity of hyperglycemia (20) and is reversible by the normalization of glycemia through the diet or with the use of sulfonylurea (21). However, we cannot rule out the possibility of the existence of an intrinsic defect in beta cells among subjects at high risk to develop non-insulin dependent diabetes mellitus that will not manifest overtly while normoglycemia is maintained.

We found that first-degree relatives of patients with NIDDM, who are at high risk to develop the disease, presented high proinsulin and insulin levels in an assay that does not cross-react with proinsulin, reflecting insulin resistance and no dysfunction of a qualitative nature in $\beta$-cells.

\section{References}

1. Martin BC, Warran J H, Rosner B, Rich SS, Soelner J S \& Krolewsky AS (1992). Familial clustering of insulin sensitivity. Diabetes, 41: 850-854.

2. Haffner SM, Stern MP, Dunn J, Mobly M, Blackell J \& Bergman RN (1990). Diminished insulin sensitivity and increased insulin responses in nonobese nondiabetic Mexican-Americans. Metabolism, 39: 842-847.

3. Zimmett PZ, Collins VR, Derse GK \& Knight LT (1992). Hyperinsulinemia in youth is predictor of type II diabetes mellitus. Diabetologia, 35: 534-541.

4. WHO Study Group: Diabetes Mellitus (1985). World Health Organization. Technical Report Series No. 727, Geneva.

5. Trinder P (1969). Determination of blood glucose using an oxidase-peroxidase system with a non-carcinogenic chromogen. J ournal of Clinical Pathology, 22: 158-161.

6. Dalbosco IS, Vieira JGH, Nishida SK, Lombardi MT, Moisés RCS, Coifman R \& Russo EMK (1996). A specific and highly sensitive time-resolved fluoroimmunoas- say for human proinsulin. Brazilian J ournal of Medical and Biological Research, 29: 193-199.

7. Vieira J GH, Nishida SK, Lombardi MT, Tashibara TT, Obara LH, Dalbosco IS \& Russo EMK (1995). Comparison of the determination of insulin by a monoclonal antibody-based immunoflurometric assay and by radioimmunoassay. Brazilian J ournal of Medical and Biological Research, 28: 537-547.

8. Wynn V \& Door T (1966). Some effects of oral contraceptives on carbohydrate metabolism. Lancet, 2: 715-719.

9. Kosaka K, Hagura R \& Kuzuya T (1977). Insulin responses in equivocal and definitive diabetes with special reference to subjects who had mild glucose intolerance but later developed definitive diabetes. Diabetes, 26: 944-952.

10. Matthews DR, Hosker J P, Rudenski AS, Naylor BA, Treacher DF \& Turner RC (1985). Homeostasis model assessment: insulin resistance and beta cell function from fasting plasma glucose and insulin concentration in man. Diabetologia, 28 : 412-419.

11. Gelding SV, Niththyanantran R, Chan SP, Skinner E, Robinson S, Gray IP, Mather H \& J ohnston DG (1994). Insulin sensitivity in non-diabetic relatives of patient with non-insulin-dependent diabetes from two ethnic groups. Clinical Endocrinology, 40: 56-62.

12. Roder ME, Eriksson J , Harthing SG, Groop L \& Binder L (1993). Proportional proinsulin responses in first-degree relatives of patient with type 2 diabetes mellitus. Acta Diabetologica, 30: 132-137.

13. Haffner SM, Stern MP, Mittenen $H$, Gienferich R \& Bowsher RR (1995). Higher proinsulin and specific insulin both associated with a parental history of diabetes in non diabetic Mexican-American subjects. Diabetes, 14: 1156-1166.

14. Kahn SE, Leonetti DL, Prigeon RL, Boyko EJ , Bergstron RW \& Fujimoto WY (1995). Proinsulin is a marker for the development of NIDDM in J apanese-American men. Diabetes, 44: 173-179. 
15. Haffner SM, Miettinen $\mathrm{H} \&$ Stern MP (1996). Nondiabetic Mexican-Americans do not have reduced insulin responses relative to nondiabetic non-hispanic whites. Diabetes Care, 19: 67-69.

16. Philips DIW, Clark PM, Hales CN \& Osmond C (1994). Understanding oral glucose tolerance: comparison of glucose or insulin measurements during the oral glucose tolerance test with specific measurements of insulin resistance and secretion. Diabetic Medicine, 11: 286-292.

17. Haffner SM, Bowsher RR, Mykkänen L, Hazuda P, Mitchell BD, Valdez RA, Geurich R, Monterrosa A \& Stern MP (1994). Proinsulin and specific insulin con- centration in high and low risk populations for NIDDM. Diabetes, 43: 14901493.

18. Reaven $\mathrm{GH}$, Chen YDI, Mollembeck $\mathrm{CB}$, Sheen WHH, Ostrega D \& Polonsky KS (1993). Plasma insulin, C-peptide, and proinsulin concentrations in obese and nonobese individuals with varying degrees of glucose tolerance. J ournal of Clinical Endocrinology and Metabolism, 76: 44-48.

19. Saad MF, Kahn SE, Nelson RG, Pettit DJ , Kwowler WC, Schartz MW, Kowalik S, Bennet PH \& Porte J r D (1990). Disproportionally elevated proinsulin in Pima Indians with non-insulin-dependent diabetes mellitus. J ournal of Clinical Endocrinology and Metabolism, 70: 12471253.

20. Birkland KI, Torjesen PA, Eriksson J, Vaaler S \& Groop L (1994). Hyperinsulinemia of type II diabetes is not present before the development of hyperglycemia. Diabetes Care, 17: 1307-1310.

21. Davies MJ , Metcalfe J, Day J L, Grenfeld A, Hales CN \& Gray J P (1994). Effect of sulphonylurea therapy on plasma insulin, intact proinsulin and 32-33 split proinsulin in subjects with type II diabetes mellitus. Diabetic Medicine, 11: 293-298. 